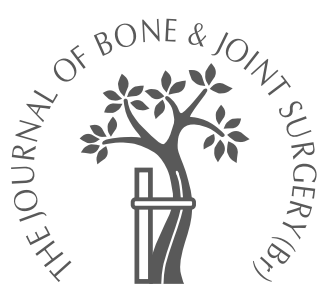

J. S. Kim, G. H. Baek, M. S. Chung, P. W. Yoon

From Seoul National University College of Medicine, Seoul, Korea

\title{
Multiple congenital brachymetatarsia
}

\author{
A ONE-STAGE COMBINED SHORTENING AND LENGTHENING \\ PROCEDURE WITHOUT ILIAC BONE GRAFT
}

\begin{abstract}
We performed nine metatarsal and three proximal phalangeal lengthenings in five patients with congenital brachymetatarsia of the first and one or two other metatarsal bones, by a one-stage combined shortening and lengthening procedure using intercalcary autogenous bone grafts from adjacent shortened metatarsal bones. Instead of the isolated lengthening of the first and the other metatarsal bones, we shortened the adjacent normal metatarsal and used the excised bone to lengthen the short toes, except for the great toe, to restore the normal parabola. One skin incision was used. All the operations were performed bilaterally and the patients were followed up for a mean period of 69.5 months (29 to 107). They all regained a nearly normal parabola and were satisfied with the cosmetic results.

Our technique is straightforward and produces good cosmetic results. Satisfactory, bony union is achieved, morbidity is low, and no additional surgery is required for the removal of metal implants.
\end{abstract}

Congenital brachymetatarsia is defined as an abnormal shortening of a metatarsal bone caused by premature closure of the epiphysis. The incidence varies greatly, but there is a strong predominance of the female gender with a female to male ratio of 98:4. In addition, $72 \%$ of cases are bilateral. ${ }^{1}$ The fourth toe is most commonly involved, although any or multiple metatarsals may be affected. As the deformity progresses, it may cause pain because of an altered metatarsal parabola. In young women the major concern is cosmetic.

Many surgical procedures for brachymetatarsia have been described. The most widely used is either one-stage lengthening with intercalcary bone graft or gradual lengthening by callus distraction. The advantages of the former over the latter are a shorter period to bony union and a smaller scar. Possible disadvantages include donor-site morbidity after a bone graft, possible neurovascular impairment caused by rapid stretching, and a small gain in length because of the tension exerted by the surrounding soft tissues. The main advantages of gradual lengthening by callus distraction include the fact that there is no need for bone grafting and there is easier stretching of tendons, fewer neurovascular complications, and early weight-bearing. The disadvantages include stiffness and deformity of the adjacent joint, scars at the pin sites, temporary hyperpigmentation of skin around the pin sites, pin-track infection, and a longer time for bony union. ${ }^{2}$ Baek and Chung ${ }^{3}$ reported success with onestage lengthening using an intercalcary bone graft and Choi et $\mathrm{al}^{4}$ reported little difference in the outcome of one-stage lengthening and callotasis in terms of length gained, percentage increase in length, and complications. They did note that the period to achieve bony union was longer in the callotasis group.

Instead of adopting isolated lengthening of the first and one or two other metatarsal bones, we shortened the adjacent normal metatarsal bones, and used the excised bone to lengthen the short toes, except for the great toe, to restore a normal parabola. The technique involves only one skin incision, is straightforward and produces good cosmetic results. Bony union is achieved sooner, morbidity is reduced, and there is no need for additional surgery to remove a metal implant.

\section{Patients and Methods}

Between 1994 and 2001, five patients with congenital brachymetatarsia of the first and one or two metatarsals were treated by a onestage combined shortening and lengthening procedure using an intercalcary autogenous bone graft from an adjacent metatarsal (Fig. 1). All were women with a mean age of 15.8 years (10 to 26). In all patients, multiple metatarsals were involved bilaterally, four patients had short first and fourth metatarsals and one 


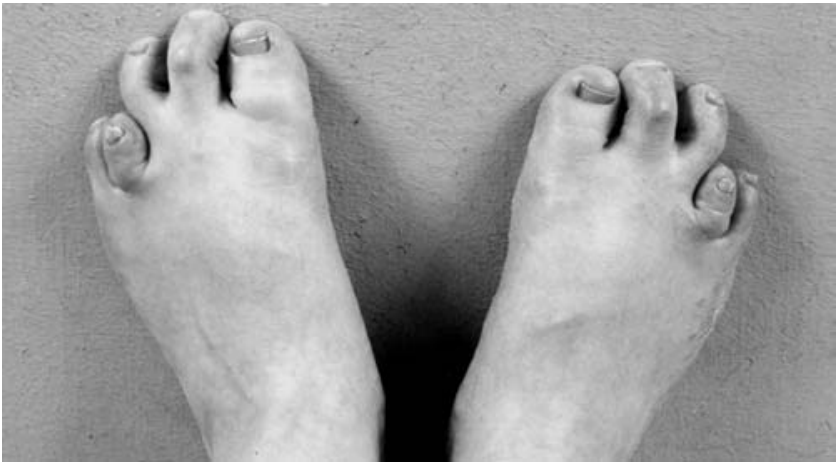

Fig. 1a

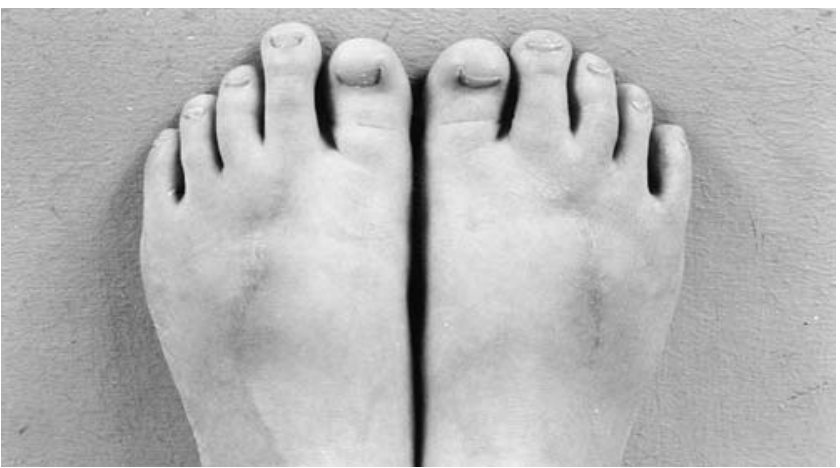

Fig. 1b

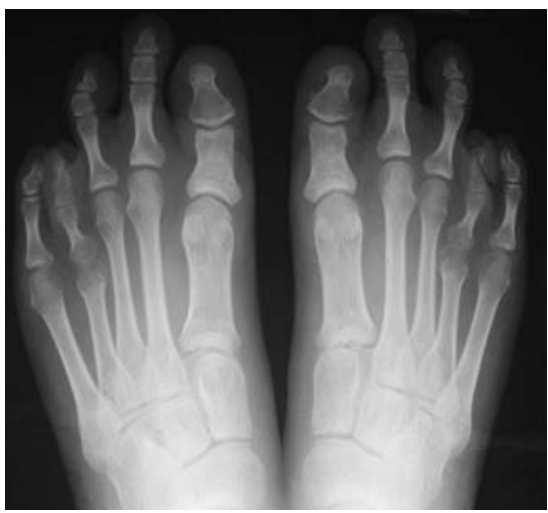

Fig. 1c

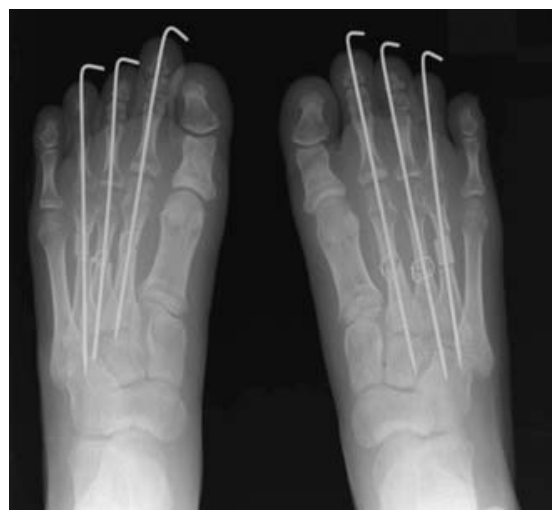

Fig. 1d

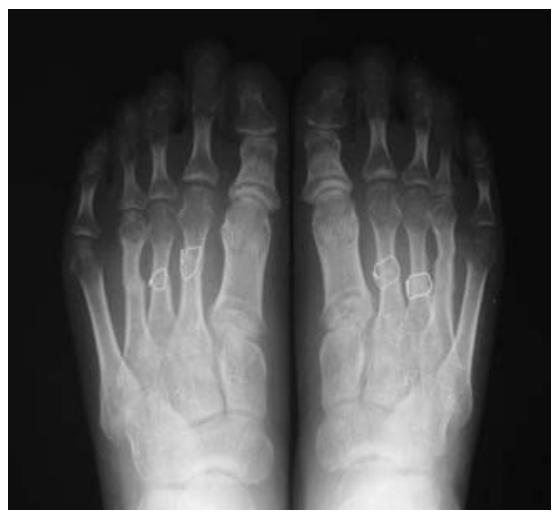

Fig. 1e

Photographs of a 26-year-old woman (case 5) with brachymetatarsia of the first and fourth toes bilaterally a) before and b) three years and nine months after operation. Radiographs showing an anteroposterior view c) before operation d) after one-stage lengthening of the fourth metatarsal bone using intercalcary autogenous bone graft from shortened second and third metatarsal bones and e) three years and nine months after operation.

had short first, fourth and fifth metatarsals. All complained of the cosmetic appearance of the short toes, but had no pain or functional discomfort. None had plantar callosities. Four had associated bilateral brachymetacarpia, and two had had surgical correction.

We shortened the adjacent metatarsal bone, and used excised bone to lengthen the short toe. All operations were performed bilaterally. After operation, patients were followed up for a mean of 69.5 months (29 to 107).

Operative technique. Before operation, we estimated the length of the osteotomy required for a normal parabola. Using a pneumatic tourniquet, a dorsal lazy ' $S$ ' incision was made over the second web space, and the interosseous muscles on both sides of the second and third toes were detached by sharp dissection. The extensor tendons were retracted and the metatarsal shaft exposed subperiosteally. Based on the pre-operative measurements, the second and third metatarsals were marked. Two holes for wire fixation were made at the proximal and distal end of predesigned osteotomy sites. The second and third metatarsals were shortened by the estimated length, thus creating a cylindrical bony segment for grafting. The proximal and distal bony segments of the shortened metatarsals were then fixed by wiring. The affected metatarsal was divided transversely at the level of the midshaft, and a Kirschner wire of $0.16 \mathrm{~cm}$ was passed into the metatarsal head from the site of the osteotomy of the distal fragment, and then distally through the proximal, middle and distal phalanges. The wire was retrieved distally and passed proximally until its tip was observed at the surface of the osteotomy. This prevented subluxation of the metatarsophalangeal and interphalangeal joints during distraction. The site of the osteotomy was then gradually distracted using a bone spreader for 20 to 30 minutes to reduce soft-tissue tension. Usually, an initial distraction of 7 or $8 \mathrm{~mm}$ was easily achieved. The ratchet of the spreader was then used for further distraction. Every click of the ratchet was approximately equivalent to 1.5 $\mathrm{mm}$ and it took three minutes to maintain every click. The excised bone from the second metatarsal was then shaped to fill the gap in the lengthened bone and predrilled to allow easy passage of the K-wire. It was placed in the gap of the distracted osteotomy site and the wire passed across to achieve fixation from the distal phalanx to the base of the metatarsal or adjacent tarsal bone.

The wires which fixed the proximal and distal ends of the second and third metatarsals were tightened, and 
Table I. Details of one-stage combined shortening and lengthening in the five patients

\begin{tabular}{|c|c|c|c|c|c|c|c|c|c|}
\hline Case & $\begin{array}{l}\text { Age } \\
\text { (yrs) }\end{array}$ & Gender & Involvement & Shortening* & Lengthening* & $\begin{array}{l}\text { Length gain* } \\
(\mathrm{mm})\end{array}$ & $\begin{array}{l}\text { Plt } \\
\text { (\%) }\end{array}$ & $\begin{array}{l}\text { Follow-up } \\
\text { (mths) }\end{array}$ & $\begin{array}{l}\text { Healing index } \\
(\mathrm{mth} / \mathrm{cm})\end{array}$ \\
\hline 1 & 14 & $\mathrm{~F}$ & Both 1st, 4th & Both 2nd, 3rd MT & Both 4th MT & $\begin{array}{l}R, 11 \\
L, 11\end{array}$ & $\begin{array}{l}24 \\
24\end{array}$ & 107 & $\begin{array}{l}2.1 \\
2.1\end{array}$ \\
\hline 2 & 16 & $\mathrm{~F}$ & Both 1st, 4th, 5th & Both 2nd, 3rd MT & $\begin{array}{l}\text { R 4th MT } \\
\text { L 4th PP }\end{array}$ & $\begin{array}{l}R, 9 \\
L, 8\end{array}$ & $\begin{array}{l}19 \\
57\end{array}$ & 74 & $\begin{array}{l}2.2 \\
2.5\end{array}$ \\
\hline 3 & 10 & $\mathrm{~F}$ & Both 1st, 4th & Both 2nd, 3rd MT & Both 4th MT & $\begin{array}{l}\text { R, } 11 \\
\text { L, } 10 \\
\text { R MT, } 11\end{array}$ & $\begin{array}{l}27 \\
23 \\
22\end{array}$ & $\begin{array}{l}90 \\
29\end{array}$ & $\begin{array}{l}1.6 \\
1.8 \\
1.7\end{array}$ \\
\hline 4 & 13 & $\mathrm{~F}$ & Both 1st, 4th & $\begin{array}{l}\text { Both 2nd, 3rd } \\
\text { MT, 5th PP }\end{array}$ & $\begin{array}{l}\text { Both 4th MT, } \\
\text { Both 4th PP }\end{array}$ & $\begin{array}{l}\text { L MT, } 11 \\
\text { R PP, } 5 \\
\text { L PP, } 8\end{array}$ & $\begin{array}{l}24 \\
38 \\
38\end{array}$ & & $\begin{array}{l}1.7 \\
3.8 \\
2.4\end{array}$ \\
\hline 5 & 26 & $\mathrm{~F}$ & Both 1st, 4th & Both 2nd, 3rd MT & Both 4th MT & $\begin{array}{l}R, 12 \\
L, 11\end{array}$ & $\begin{array}{l}22 \\
21\end{array}$ & 45 & $\begin{array}{l}1.7 \\
1.8\end{array}$ \\
\hline
\end{tabular}

* MT, metatarsals; PP, proximal phalanges; $R$, right; $L$, left

$\dagger \mathrm{Pl}$, percentage increase

another from the distal phalanx to the metatarsal base was inserted into the second and third toes. In one case, the normal parabola was not achieved on the left side after metatarsal lengthening, and therefore an additional lengthening of the proximal phalanx of the fourth toe was performed.

A below-knee walking cast was retained for four to eight weeks when radiographs showed solid union. The K-wires were removed after seven to ten weeks. Full weight-bearing was allowed at eight weeks after operation.

\section{Results}

In the 12 bones of the five patients, the mean percentage increase gain in length was $28.3 \%$ (19 to 57 ). The mean healing index, which was defined as the time to solid bony union, was 2.1 months/cm (1.6 to 3.8). The mean duration of the operation was 206 minutes (170 to 236). In all patients, good functional metatarsal parabolas were restored and no complications were reported. All the patients were satisfied with the cosmetic results and were able to walk on tiptoe, and had no limitation of daily activities (Table I).

\section{Discussion}

Brachymetatarsia has a strong female predominance, but this may be misleading, because the usual presenting complaint is the cosmetic appearance. Thus, the goal of treatment is to obtain a good cosmetic result.

In 1971, Lelievre ${ }^{5}$ evaluated the metatarsal parabola and reported that the first and second metatarsals should be equal in length, and the remaining lesser metatarsals should show a gradually reducing length (i.e. $1=2>3>4>5$ ).

Fox ${ }^{6}$ addressed the three main goals of the surgical correction of brachymetatarsia: 1) alleviation of pain, 2) the establishment of a cosmetically acceptable foot, and 3 ) the restoration of a functional metatarsal parabola. However, four of our patients had no pain, and their major concern was to have a cosmetically acceptable foot. Because all the cases were bilateral, multiple skin incisions and at least four or more external fixators would have been needed for an extended period of time to lengthen the short metatarsals by callus distraction. One-stage lengthening with autogenous iliac bone graft would have been the other treatment of choice, but a large amount of bicortical bone would have been required to recreate the normal parabola, and donor-site morbidity with pain and a large additional scar, presented a further problem.

We used one incision, which reduced scarring. Since the relatively long adjacent metatarsals were shortened, the gain in length required to obtain a normal metatarsal parabola was less than that using other methods. Moreover, this reduction in length gain may lower the risk of neurovascular complications. Since all the operations were performed bilaterally, all the patients were satisfied with their symmetrical feet. No data are available about brachymetatarsia with multiple metatarsal involvement. Some authors have presented case reports of a combined shortening and lengthening metatarsal osteotomy for the treatment of brachymetatarsia ${ }^{7,8}$ but there is no series of cases with longterm follow-up in the literature and the technique described here has not been previously reported.

No benefits in any form have been received or will be received from a commercial party related directly or indirectly to the subject of this article.

\section{References}

1. Urano Y, Kobayashi A. Bone-lengthening for shortness of the fourth toe. J Bone Joint Surg [Am]1978;60-A:91-3

2. Masada K, Fujita S, Fuji T, Ohno H. Complications following metatarsal lengthening by callus distraction for brachymetatarsia. J Pediatr Orthop 1999;19:394-7.

3. Baek GH, Chung MS. The treatment of congenital brachymetatarsia by one-stage lengthening. J Bone Joint Surg [Br] 1998;80-B:1040-4.

4. Choi IH, Chung MS, Baek GH, Cho TJ, Chung CY. Metatarsal lengthening in congenital brachymetatarsia: one-stage lengthening versus lengthening by callotasis. J Pediatr Orthop 1999;19:660-4.

5. Lelievre J. Pathologie du pied physiologie, clinique, traitment medicale orthopedique et chirurgical. Paris: Masson, 1971.

6. Fox IM. Treatment of brachymetatarsia by the callus distraction method. J Foot Surg 1998;37:391-5.

7. Goforth WP, Overbeek TD. Brachymetatarsia of the third and fourth metatarsals J Am Podiatr Med Assoc 2001;91:373-8.

8. Handelman RB, Perlman MD, Coleman WB. Brachymetatarsia: a review and case report. J Am Podiatr Assoc 1986;76:413-16. 